\title{
Development of electrochromic cells by the sol-gel process
}

\author{
B. Munro*, P. Conrad, S. Krämer, H. Schmidt, P. Zapp \\ Institut für Neue Materialien, Universität des Saarlandes, Gebaude 43, Im Stadtwald D-66123, Saarbrücken, \\ Germany
}

\begin{abstract}
These investigations have the development of electrochromic cells via the sol-gel process as their objective. Syntheses routes for tungsten oxide, $\mathrm{WO}_{3}$, coating sols and cerium oxide-titanium oxide sols, $\mathrm{CeO}_{2}-\mathrm{TiO}_{2}$, were developed, which enabled indium-tin oxide (ITO) coated glass substrates to be coated homogeneously and without visible cracking. Optoelectrochemical measurements were employed to determine the variation of the electrochromic properties (change in optical density, $\Delta \mathrm{OD}$, and switching times) of $\mathrm{WO}_{3}$ layers, investigated as a function of coating parameters, such as chamber humidity and the temperature of heat treatment. A novel nanocomposite electrolyte system, based on organically modified silanes, was developed, which has an ionic conductivity of $10^{-4}-10^{-5} \mathrm{~S} \mathrm{~cm}^{-1}$ at $25^{\circ} \mathrm{C}$. Values of diffusion coefficients for lithium ions in tungsten oxide layers could be determined by electrochemical impedance spectroscopy (EIS) and lie in the range $10^{-11}-10^{-12} \mathrm{~cm}^{2} / \mathrm{s}$. The values obtained are comparable with literature values for $\mathrm{WO}_{3}$ layers deposited by sputtering. The cells which have been constructed to date show a typical reduction in transmission from $80 \%$ to $20 \%$ with a half-life of less than $30 \mathrm{~s}$, where half-life is here defined as the time necessary for half of the change in transmission to be obtained, i.e. from $80 \%$ to $50 \%$
\end{abstract}

Keywords: Electrochromic cells; Sol-gel process

\footnotetext{
*Corresponding author. E-mail: munro@inm-sb.de
} 


\section{Introduction}

The overall objective of this current project is to develop a complete electrochromic system based on sol-gel technology. Whereby, the processability of sol-gel materials as layered systems, for two separate applications (rear-view mirrors and smart windows), is to be demonstrated. Applications-related aims include the optimisation of the properties of the coating materials (rheology, potlife etc.), the electrochemical characterisation of cells, the investigation of the long-term behaviour and the development of suitable techniques for coating large-areas.

The state of the art can be best judged by the devices, which are commericially available. An example of a small area device are the electrochromic sunglasses from NIKON in Japan, which function with a hydrated oxide as electrolyte. Rear-view mirrors on the other hand are available from GENTEX, which rely on a liquid electrolyte. Both types of devices are unsuitable for scaling-up to large areas. Thin solid electrolyte layers e.g. $\mathrm{Ta}_{2} \mathrm{O}_{5}$ are difficult to prepare without pin-holes or other defects over large areas, so that mirror-sized devices probably set the limit for this type of electrolyte. In addition, the tungsten oxide layer was prepared by physical deposition methods, which are too uneconomic for scaling-up to larger areas. Liquid electrolytes although maybe satisfactory for small devices are for safety reasons not permissible for architectural or automobile glazing. Polymer electrolytes suffer from problems of insufficient UV-stability.

To solve these problems, a system has been developed by INM, consisting of sol-gel $\mathrm{WO}_{3}$ as the electrochromic layer, a novel lithium-ion-conducting electrolyte based on inorganic-organic nanocomposites, and a $\mathrm{CeO}_{2}-\mathrm{TiO}_{2}$ ion-storage layer as first proposed by Baudry et al. [1], with ITO-coated glass as the substrate material. Preparation of the EC layer and the counter electrode layer by the sol-gel method allows large areas to coated a relatively low cost and the nanocomposite layer, based on organically modified silanes has a better UV-stability than polymer electrolytes.

\section{Experimental}

\subsection{Synthesis: EC-layer}

Stable coating sols for $\mathrm{WO}_{3}$ were prepared, employing a modified synthesis, based on the reaction of tungsten metal powder with an excess of hydrogen peroxide solution ( $30 \%$ solution), to give the peroxotungstic acid, in the presence of ethanol and glacial acetic acid. Similar routes for the preparation of coating sols suitable for dip-coating have already been reported [2]. The reaction is conducted, with appropriate cooling, to keep the temperature at $0^{\circ} \mathrm{C}$. The clear yellow sol, which is formed, can be evaporated to dryness and the powder redispersed in ethanol as required. Up to 25 wt $\%$ of powder, can be redispersed in this way and the coating sol thus produced can be stored for several weeks at $6^{\circ} \mathrm{C}$ without any detrimental effect on the coating properties. 
ITO-substrates from Donnelly Applied Films $(R<20 \Omega / \square)$ were coated by dipcoating (withdrawal speeds between 2 and $10 \mathrm{~mm} \mathrm{~s}$ ) under controlled temperature $\left(20^{\circ} \mathrm{C}\right)$ and relative humidity (selected between 10 and $\left.50 \%\right)$ conditions. The substrates then underwent a heat treatment of either 1 or $2 \mathrm{~h}$ at $120^{\circ} \mathrm{C}$ or $240^{\circ} \mathrm{C}$. Thin films could be prepared in a single coating step, which were crack-free and of an excellent optical quality. Depending on the exact conditions the thickness of the coatings could be varied between 200 and $400 \mathrm{~nm}$.

\subsection{Synthesis: Ion-insertion layer, $\mathrm{CeO}_{2}-\mathrm{TiO}_{2}$}

A sol-gel route was employed based on titanium isopropylate, $\operatorname{Ti}\left(\mathrm{O}^{\mathrm{i}} \mathrm{Pr}\right)_{4}$, and cerium nitrate hexahydrate, $\mathrm{Ce}\left(\mathrm{NO}_{3}\right)_{3} \cdot 6 \mathrm{H}_{2} \mathrm{O}$, as precursors. A mixture of the precursors in alcohol is heated under reflux for a specific length of time in order to achieve sols with a definite particle size and viscosity. Crack-free coatings with a reproducible thickness of $140 \mathrm{~nm}$ could be obtained by dip coating, in a single step, after thermal treatment at $400^{\circ} \mathrm{C}$.

\subsection{Synthesis: Nanocomposite electrolyte}

A solid ionic conductor has been developed, based on glycidoxypropyltrimethoxysilane (GPTS), tetraethoxysilane (TEOS), $\mathrm{LiClO}_{4}, \mathrm{Zr}\left(\mathrm{O}^{n} \mathrm{Pr}\right)_{4}$ and tetraethylene glycol (TEG). GPTS and TEOS serve as network formers, whereas TEG acts as a plasticizer. Lithium perchlorate is the conducting salt and $\mathrm{Zr}\left(\mathrm{O}^{n} \mathrm{Pr}\right)_{4}$ is added as a starter for thermal curing. Dried $\mathrm{LiClO}_{4}$ is dissolved in a mixture of TEG and prehydrolysed GPTS. TEOS and $\mathrm{Zr}\left(\mathrm{O}^{n} \mathrm{Pr}\right)_{4}$ are then added. Volatiles are removed by rotary evaporation immediately prior to the application to the coated ITO-substrates. The cell containing electrolyte is heat treated at $100^{\circ} \mathrm{C}$ for several hours to allow thermal curing to occour. The thickness of the electrolyte layer is approximately $10 \mu \mathrm{m}$.

\subsection{Optoelectrochemical characterisation}

In order to study the colouration and bleaching kinetics of the $\mathrm{WO}_{3}$-layers, $\mathrm{WO}_{3}$-coated ITO-substrates were placed in three electrode cells containing liquid electrolyte $\left(\mathrm{LiClO}_{4} / \mathrm{PC}\right)$ and switched at a variety of potentials as referenced against a $\mathrm{Ag} / \mathrm{AgClO}_{4}$ electrode. On switching, the average transmission (without adjustment for the sensitivity of the human eye) over the wavelength range 380-800 nm was measured as a function of time, employing a multichannel UV-VIS spectrometer (ZEISS SPECORD S10). Colouring times were defined as the time between $90 \%$ of the initial transmission, $T_{0}$, and $110 \%$ of the final transmission, $T_{x}$, bleaching times were similarly defined. The change in optical density, $\triangle \mathrm{OD}$, was also taken as an important criterion for assessing the electrochromic layers, whereby

$$
\Delta \mathrm{OD}_{x}^{(380-800 \mathrm{~nm})}=\log \left(T_{0}^{(380-800 \mathrm{~nm})} / T_{x}^{(380-800 \mathrm{~nm})}\right)
$$


The variation in $\triangle \mathrm{OD}$ and in the switching times were investigated as function of the number of cycles.

\subsection{Electrochemical impedance spectroscopy}

The conductivity of the electrolyte samples was determined by impedance spectroscopy employing a HP 4192 Impedance Analyser in a frequency range of $1 \mathrm{~Hz}$ to $1 \mathrm{Mhz}$. Impedance spectroscopy was also used to determine values of chemical diffusion coefficient for $\mathrm{Li}^{+} / \mathrm{H}^{+}$in the $\mathrm{WO}_{3}$ layers as according to the method described by $\mathrm{Ho}$ et al. [3]. For this purpose, $\mathrm{WO}_{3}$-coated ITO substrates were coloured in a three electrode cell, containg liquid electrolyte $\left(\mathrm{LiClO}_{4} / \mathrm{PC} / \mathrm{H}_{2} \mathrm{O}\right)$ at a potential of $-1.2 \mathrm{~V}$, as measured against a $\mathrm{Ag} / \mathrm{AgClO}{ }_{4}$ reference electrode. After several hours, during which the current had sunk to a few $\mu \mathrm{A}$, impedance spectra were collected with a Zahner IM5d Electrochemical Impedance Analyser. The chemical diffusions coefficient, $D$, could be calculated from linear part of the impedance plot (Warburg impedance) according to

$$
|Z|=\left|\left(\left(V_{\mathbf{M}}(\mathrm{d} E / \mathrm{d} y) \omega^{-\frac{1}{2}}\right) /\left(\mathrm{zF} D^{\frac{1}{2}} a\right)\right)\right|
$$

where $V_{M}$ is the molar volume in $\mathrm{cm}^{3}, \mathrm{~d} E / \mathrm{d} y$ the change in stoichiometry as a function of the potential and $a$ is the area; $\omega, z, F$, have their normal meanings.

\section{Results and discussion}

\section{1. $\mathrm{WO}_{3}$-layers}

The peroxotungstic acid route offers several advantages over other possible syntheses using other precursors. The chemical costs are low in comparison to tungsten alkoxides and relatively thick homogenous layers can be obtained at low heating temperatures $\left(120-240^{\circ} \mathrm{C}\right)$. In addition, the commonly used tungsten oxychloride, $\mathrm{WOCl}_{4}$, cannot be handled without an inert or dry atmosphere. Fig. 1 shows the change in transmission on colouring, averaged over the spectral range 380-800 nm, of $\mathrm{WO}_{3}$ layers, prepared under varying conditions, for the first switching cycle. The layers were heat treated at $120^{\circ} \mathrm{C}$ and the speed of withdrawal was $4 \mathrm{~mm} / \mathrm{s}$. Layers heated at $120^{\circ} \mathrm{C}$ showed faster colouration and bleaching kinetics than those heated at $240^{\circ} \mathrm{C}$. In addition, these coatings exhibited a dependence on the relative humidity in the chamber during dipping.

The effect of the relative humidity in the coating chamber on the colouration of the $\mathrm{WO}_{3}$-layers in the first switching cycle does not seem to be significant. Only a modest increase of the speed of colouration is observed with increasing humidity, indicating the influence of $\mathrm{H}^{+}$as a charge carrier. The varying duration of the heat treatment had no noticeable effect, which would suggest that $1 \mathrm{~h}$ is sufficient to attain a constant water content. The initial differences in colouring disappeared however, after several cycles. 


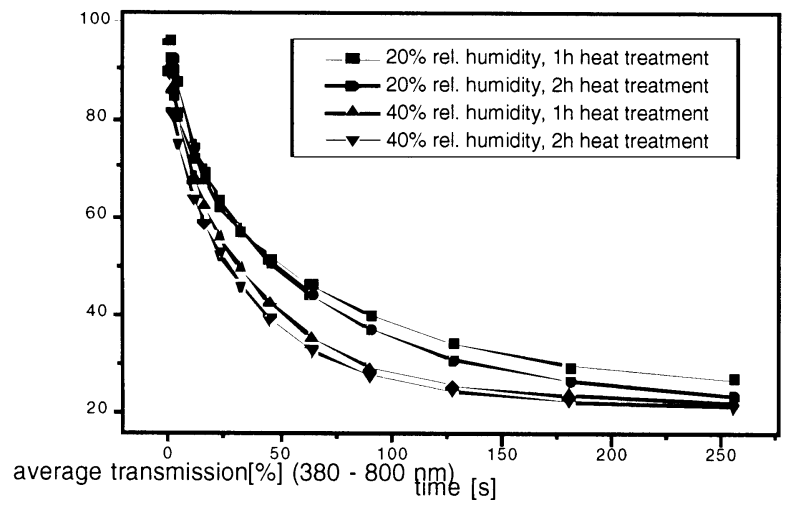

Fig. 1. Time dependence of coloration for $\mathrm{WO}_{3}$-layers prepared under varying conditions, on switching at a potential of $-1.2 \mathrm{~V}$ as referenced against a $\mathrm{Ag} / \mathrm{AgClO}_{4}$ electrode in $\mathrm{LiClO}_{4} / \mathrm{PC}$ electrolyte.

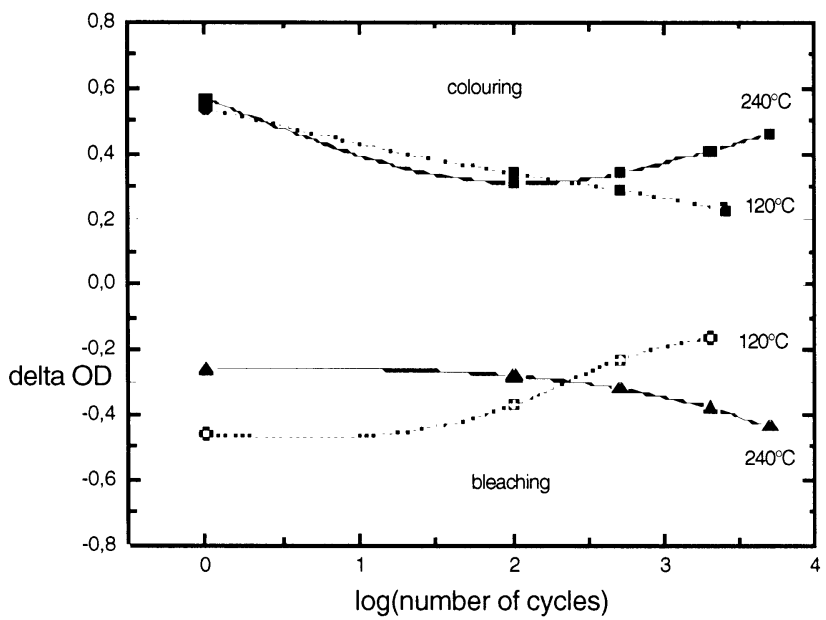

Fig. 2. $\triangle \mathrm{OD}$ plotted against the logarithm of the number of cycles for $\mathrm{WO}_{3}$-layers heated at $120^{\circ} \mathrm{C}$ and $240^{\circ} \mathrm{C}$.

Fig. 2 shows the variation in $\triangle \mathrm{OD}$ for $\mathrm{WO}_{3}$-layers heated at $120^{\circ} \mathrm{C}$ and $240^{\circ} \mathrm{C}$ as a function of the number of switching cycles (positive values of $\Delta \mathrm{OD}$ correspond to colouring and negative values represent bleaching). It can be seen from Fig. 2 that the $\mathrm{WO}_{3}$ films heated at only $120^{\circ} \mathrm{C}$ exhibit a gradual decrease in $\Delta \mathrm{OD}$ with an increasing number of cycles. This is due to the poor chemical resistance of the layers to the electrolyte medium. The behaviour seen after the first cycle, for the layers heated at $240^{\circ} \mathrm{C}$, represents the swinging-in of the layers. The large value of $\Delta \mathrm{OD}$ observed in the initial cycle is probably due to residual water in the $\mathrm{WO}_{3}$-layers. 
Table 1

Diffusion coefficients of $\mathrm{Li}^{+} / \mathrm{H}^{+}$in $\mathrm{WO}_{3}$-layers, prepared by the sol-gel method, sputtering or thermal evaporation

\begin{tabular}{lll}
\hline Method of preparation & $\mathrm{D}\left(\mathrm{cm}^{2} \mathrm{~s}\right)$ & Reference \\
\hline Sol-gel & $5.0 \times 10^{-11}$ & This work \\
Sputtering & $2.6 \times 10^{-11}$ & {$[3]$} \\
Evaporation & $2,8 \times 10^{-11}$ & {$[3]$} \\
\hline
\end{tabular}

Diffusion coefficients were determined for $\mathrm{WO}_{3}$-layers, which had been heated at $200^{\circ} \mathrm{C}$, by means of electrochemical impedance spectroscopy (EIS) [3,4]. Although many separate processes contribute to the electrochromic effect (charge transfer, ion migration etc). Chemical diffusion is usually the slowest and thus rate-determining step, which has the greatest influence on the switching times. Chemical diffusion coefficients are more useful as a value for comparison with literature values than switching times as these have not been defined in a standard manner. A wide range of values of diffusion coefficients has been reported from $10^{-9} \mathrm{~cm}^{2} / \mathrm{s}[5]$ to $10^{-13} \mathrm{~cm}^{2} / \mathrm{s}$ [6], whereby the water content of the layers or the type of preparation varies or as in Ref. [6] the value was determined for crystalline $\mathrm{WO}_{3}$. Values also can vary according to the measurement method. The average value obtained for the sol-gel layers presented here are therefore displayed in Table 1, alongside values from the literature, which were acquired under similar measurement conditions.

The values agree with literature values for sputtered or evaporated layers and consistent with measurements made in $\mathrm{LiClO}_{4} / \mathrm{PC}$ where traces of water are present.

\subsection{Conductivity of electrolyte}

An electrolyte system based on organically modified silanes was chosen in order to combine the thermal and UV-stability of an inorganic material with the polymerisability of an organic system. The addition of TEOS leads to the formation of nanoparticles (diameter $20 \mathrm{~nm}$ ), providing thermodynamically stable $\mathrm{OH}$ and $\mathrm{O}-\mathrm{Li}^{+}$groups, which act as preferred sites for the charge carriers. The conductivity of the nanocomposite electrolyte ranges from $10^{-4}$ to $10^{-5} \mathrm{~S} \mathrm{~cm}^{-1}$ at $25^{\circ} \mathrm{C}$, depending on the exact composition. The conductivity of the samples exhibits a temperature dependence according to the Vogel-Tamman-Fulcher equation (VTF), as is typical for such systems. As well as possessing a reasonable ionic conductivity, the electrolyte is thermally stable well over $100^{\circ} \mathrm{C}$ and acts also as an adhesive for the glass panes.

\subsection{Key data of complete cells}

Cells were constructed in two formats: $15 \times 10 \mathrm{~cm}^{2}$ and $35 \times 35 \mathrm{~cm}^{2}$. Tests on the smaller cells gave a constant change in optical density of 0.6 or a change in transmission from $80 \%$ to $20 \%$ in a switching time of less than $100 \mathrm{~s}$, after the initial 
swinging-in of the cells. The cells were coloured potentiostatically at $-2.5 \mathrm{~V}$. The colouration of the cells remained homogeneous on scaling-up to the larger format.

\section{Summary and conclusions}

Sol-gel technology could be exploited to prepare electrochromic cells with excellent properties. The preparation of the $\mathrm{WO}_{3}$-coatings was optimised using optoelectrochemical methods. The properties of the sol-gel $\mathrm{WO}_{3}$-layers are very similar to those of layers prepared by physical deposition methods. Cells of the following construction: ITO $/ \mathrm{WO}_{3} /$ electrolyte $/ \mathrm{CeO}_{2}-\mathrm{TiO}_{2} / \mathrm{ITO}$ were assembled in two formats: $15 \times 10 \mathrm{~cm}^{2}$ and $35 \times 35 \mathrm{~cm}^{2}$.

\section{Acknowledgements}

The authors would like to thank the German Ministry for Education and Research (BMBF) for their financial support of this project. Thanks are also due to the companies Bischoff Glastechnik (BGT) and Donnelly HOHE for permitting the publication of these results.

\section{References}

[1] P. Baudry, A.C.M. Rodrigues, M.A. Aegerter, L.O. Bulhoes, J. Non-Cryst. Solids 121 (1990) 319.

[2] M. Desesuk, J.P. Cronin, S.R. Kennedy, K.L. law, G.F. Nielson, D.R. Uhlmann, 52/SPIE vol. 2255.

[3] C. Ho, I.D. Raistrick, R.A. Huggins, J. Electrochem. Soc. 127 (2) (1980) 343.

[4] D.R. Franceschetti, J.R. Macdonald, J. Electrochem. Soc. 129 (8) (1982) 1754.

[5] S.K. Mohapatra, J. Electrochem. Soc. 125 (1978) 284.

[6] M. Green, D.C. Smith, J.A. Weiner, Thin Solid Films 38 (1976) 89. 